\title{
Hepatitis B virus infection and 1q21 amplification in multiple myeloma
}

\author{
DAN GUO ${ }^{1,2^{*}}$, PEIPEI XU ${ }^{2 *}$, CHAOYANG GUAN ${ }^{2 *}$, YONG XU $^{2}$, YONGGONG YANG $^{2}$, \\ JINGYAN XU ${ }^{2}$, RONGFU ZHOU ${ }^{2}$ and BING CHEN ${ }^{2}$ \\ ${ }^{1}$ Department of Hematology, Affiliated Hospital of Nantong University, Nantong, Jiangsu, 226001; \\ ${ }^{2}$ Department of Hematology, Nanjing Drum Tower Hospital, Clinical College of Nanjing Medical University, \\ Nanjing, Jiangsu 210029, P.R. China
}

Received September 14, 2018; Accepted February 27, 2019

DOI: $10.3892 / 01.2019 .10926$

\begin{abstract}
Hepatitis B virus (HBV) is a hepatotropic and a lymphotropic virus. An association between HBV and hematologic malignancies has been determined previously; however, the association between HBV infection and multiple myeloma (MM) remains controversial. The present study aimed to assess the prevalence of $\mathrm{HBV}$ infection in patients with $\mathrm{MM}$, and investigate their characteristics and prognostic significance. The clinical data of 165 patients with MM who had received at least four cycles of chemotherapy between April 2008 and February 2017 at Nanjing Drum Tower Hospital (Nanjing, China) were collected. HBV markers were determined using ELISA. The rates of acute or chronic HBV infection and resolved HBV infection in patients with MM were 12.12 and $26.06 \%$, respectively. The gain of 1q21 was significantly more prevalent in the patients who were classified as HBV-positive compared with the patients who were classified as HBV-negative (54 vs. 38.2\%; $\mathrm{P}=0.048$ ), and the level of alanine transaminase in patients who were classified as HBV-positive was significantly increased compared with the non-infected group (63.29 vs. $24.66 \mathrm{U} / 1$; $\mathrm{P}=0.043$ ). Lactate dehydrogenase, serum creatinine and serum calcium levels were additionally determined to be significant risk factors of overall survival. The progression-free survival (PFS) of patients who were classified as HBV-positive was decreased compared with patients who were classified as HBV-negative (18.97 vs. 29.67 months; $\mathrm{P}=0.006$ ), and being HBV-positive was determined to be an independent prognostic factor of PFS. HBV infection may contribute to MM progression through 1q21
\end{abstract}

Correspondence to: Dr Bing Chen, Department of Hematology, Nanjing Drum Tower Hospital, Clinical College of Nanjing Medical University, 321 Zhongshan Road, Nanjing, Jiangsu 210029, P.R. China

E-mail: chenbing2004@126.com

${ }^{*}$ Contributed equally

Key words: hepatitis B virus infection, multiple myeloma, 1q21 amplification amplification, and improved monitoring of HBV markers in patients with MM may be required.

\section{Introduction}

Hepatitis B virus (HBV) infection is a principal health problem worldwide. China has $\sim 170$ million individuals who are chronic HBV carriers, $10 \%$ of whom may develop chronic hepatitis (1). HBV is a hepatotropic and a lymphotropic virus, and the association between HBV and hematologic malignancies, particularly B-cell non-Hodgkin lymphoma, has been described previously $(2,3)$.

Multiple myeloma (MM) is the second-most common hematologic malignancy, involving malignant plasma cells that continuously proliferate in bone marrow (4). The treatment of MM has improved since the emergence of novel therapeutics, including proteasome inhibitors, immunomodulatory drugs and CD38 antibodies, which have improved the prognosis of patients (5). However, the etiology and pathogenesis of MM have remained unclear. MM may be associated with viral infections. Amongst the possible candidate viruses, HBV has been widely examined; however, the association between HBV infection and $\mathrm{MM}$ is controversial. Becker et al (6) observed that HBV infection is serologically positive in $15.8 \%$ of cases with MM and added MM to the list of potential virus-associated lymphoma entities. Teng et al (7) estimated that the prevalence of chronic $\mathrm{HBV}$ is $11.0 \%$ in patients with MM, and chronic hepatitis carriers exhibited poorer overall survival. However, Marcucci and Mele (3) identified that associations between HBV infection and MM are weak, as these tumors are unable to form as a consequence of the chronic antigenic stimulation of B cells.

To assess the prevalence of HBV infection and investigate the clinicopathological characteristics and prognostic significance, 165 patients with MM who had received at least four cycles of chemotherapy between April 2008 and February 2017 at Nanjing Drum Tower Hospital (Nanjing, China) were retrospectively analyzed.

\section{Patients and methods}

Patients. The diagnosis of MM was based on the criteria proposed by the International Myeloma Working Group (IMWG) (8). 
The Standard screening tests include total serum protein, serum and urine protein electrophoresis (SPEP and UPEP), immunoglobulin free light chain (FLC) in serum and bone marrow aspiration or biopsy. If a patient had monoclonal protein detected by SPEP, UPEP, or by pathological FLC ratio and the plasma cell count was $\geq 10 \%$, a diagnosis of multiple myeloma was clear. A total of 306 patients with MM were diagnosed at Nanjing Drum Tower Hospital between April 2008 and February 2017. For some patients, HBV status was unavailable or they did not receive at least four cycles of chemotherapy, so they were excluded from the present analysis. Therefore, the final data file comprised 165 patients with MM to analyze the infection of HBV and assess treatment response. The patients consisted of 88 males (53.3\%) and 77 females (46.7\%). The median age of all the subjects was 61 years (range, 40-81 years), and their median follow-up was 28.17 months (range, 5.4-90.8 months). Univariate and multivariate analyses of overall survival (OS) and progression-free survival (PFS) were conducted. Each patient was staged by Durie-Salmon (9), International Staging System (10) and Revised-ISS (11). The risk stratification of MM involved the IMWG risk stratification and the criteria for evaluating the therapeutic effects were in accordance with IMWG standards (12). All the patients were continuously followed up unless patients were lost to follow-up or they had passed away. Variables regarding clinical manifestations, laboratory tests and pathological reports were retrieved from the hospital database using a medical chart review. The Ethics Committee of Nanjing University (Nanjing, China) approved the present study and written informed consent was obtained from all the patients.

Detection method of $H B V$ infection. ELISA was used to detect the HBV markers in all the patients. HBV Casset ELISA Kit were provided by Shanghai Kehua Biological Engineering Co., Ltd. Serum hepatitis B surface antigen (HBsAg), hepatitis B surface antibody, hepatitis B e antigen, hepatitis B e antibody and hepatitis $\mathrm{B}$ core $(\mathrm{HBc})$ antibody were detected in all the participants prior to and following treatment. If HBsAg was serologically positive at diagnosis, the serum HBV DNA level was measured regularly by quantitative PCR performed on an ABI7300 Real-Time PCR System (Applied Biosystems; Thermo Fisher Scientific, Inc.). The data of HBV markers and HBV DNA were obtained from the Department of Clinical Laboratory, Nanjing Drum Tower Hospital.

Detection method of liver-associated laboratory parameters and $M$ protein. The aspartate transaminase, bilirubin, triglyceride, total cholesterol, high-density lipoprotein cholesterol and low-density lipoprotein cholesterol were detected by SMT-100 automatic biochemical analyzer (Beijing Pulang New Technology Co., Ltd., Beijing, China). The PUN-2048A semi-automatic coagulation analyzer (Beijing Pulang New Technology Co., Ltd.) was used to detect the coagulation function. Immunovelocity nephelometry was used to determine M protein by IMMAGE 800 automatic specific protein analyzer (Beckmann Kurt Company). The data were also obtained from the Department of Clinical Laboratory, Nanjing Drum Tower Hospital.

Cytogenetic analysis. Bone marrow samples were subjected to chromosome Karyotype analysis using the Giemsa-banding staining technique (13). Chromosomal abnormalities were described, according to the International System for Human Cytogenetic Nomenclature 2013 (14). Cytogenetic abnormalities included a minimum of two mitotic cells with a gain of the same chromosome or with the same structural abnormality and three mitotic cells with the loss of the same chromosome. CD138-purified plasma cells were analyzed through interphase fluorescence in situ hybridization (FISH) using probes for chromosomes 1q21, 13q14, immunoglobulin heavy locus (IGH) and P53 to detect the cytogenetic abnormality of MM. According to the manufacturer's protocol, CD138+ plasma cells were purified using anti-CD138 immunobeads and whole blood columns (Miltenyi Biotec $\mathrm{GmbH}$ ). A total of $5 \mathrm{ml}$ bone marrow was extracted and $50 \mathrm{ul}$ of anti-CD138 immunobeads were added per $\mathrm{ml}$ of bone marrow, incubated at $4^{\circ} \mathrm{C}$ for $15 \mathrm{~min}$, centrifuged at $110 \mathrm{x} \mathrm{g}$ at $25^{\circ} \mathrm{C}$ for $5 \mathrm{~min}$, the supernatant was removed, and the plasma cells were separated by column. Then, the plasma cells adsorbed on the separation column were eluted with Elution buffer (Shanghai Qcbio Science \& Technologies Co., Ltd.), and the purified plasma cells were hypotonicized at $25^{\circ} \mathrm{C}$ for $30 \mathrm{~min}$, through a $0.075 \mathrm{~m} / 1$ potassium chloride solution, and fixed at $25^{\circ} \mathrm{C}$ for $30 \mathrm{~min}$ by methanol/glacial acetic acid (3:1) three times and stored at $\sim 20^{\circ} \mathrm{C}$. The probes for chromosomes 1q21, 13q14, IGH and P53 used by FISH were purchased from Beijing Jinpujia Medical Technology Co., Ltd (Beijing, China). ThermoBrite in situ hybridization (NatureGene Corp, USA) was used to perform hybridization. A minimum of 200 interphase nuclei per probe were evaluated using Olympus BX51 fluorescence microscope. The manufacturer's protocol: cell suspensions sorted by anti-CD138 immunobeads were dripped by air-dry method (15). After baking the aged slides, they were placed in proteinase $\mathrm{K}$ buffer $(10 \mu \mathrm{g} / \mathrm{ml})$ at $45^{\circ} \mathrm{C}$ for 1 to $2 \mathrm{~h}$, and then washed with $2 \mathrm{x}$ saline-sodium citrate solution, gradient dehydration was carried out in 70,85 and $100 \%$ ethanol. After drying the glass slides, the prepared probes were added to the hybridizer and denatured at $75^{\circ} \mathrm{C}$ for $5 \mathrm{~min}$ and hybridized at $42^{\circ} \mathrm{C}$ for $16 \mathrm{~h}$. After washing with $0.1 \mathrm{NP}-40$ and $0.3-\mathrm{NP}-40$, the slides were incubated with 4,6-Diamidino-2-phenylindole (DAPI) at $25^{\circ} \mathrm{C}$ for $15 \mathrm{~min}$ in the dark for re-staining. Then, placed the processed sample under a fluorescence microscope (magnification, x40; object lens) and randomly selected a well-dispersed area and vision of cell division to observe. The hybridization signals were observed by choosing appropriate filters according to the fluorescein labeled on the Fish probe. In each case, 200-500 cells were analyzed and the percentage of positive cells with abnormal fluorescent signal was counted. If the percentage of positive cells was greater than the threshold, the result was positive. The threshold for 1q21 amplification, deletion of 13q14 and P53 and IGH rearrangements was respectively $8.09,9.01,8.57,9.19 \%$. The data of cytogenetic analysis were from Beijing Hightrust Diagnostics (Beijing, China).

Treatment for MM. All the patients were administered at least four cycles of a regimen of chemotherapy of either bortezomib or dexamethasone; bortezomib, thalidomide and dexamethasone; or dexamethasone, cyclophosphamide, etoposide and cisplatin. A total of 16 patients received autologous stem cell transplant (ASCT) subsequent to undergoing high-dose 
chemotherapy. All patients with active HBV infection and chronic HBV infection received lamivudine [0.1 g once a day (qd)], entecavir ( $0.5 \mathrm{mg} \mathrm{qd}$ ) or adefovir dipivoxil (10 mg qd) for antiviral treatment during the therapy.

Statistical analysis. SPSS 19.0 (IBM Corp., Armonk, NY, USA) was used for all statistical analyses. $\chi^{2}$ tests and Fisher's exact tests were performed to compare categorical variables, and a t-test was conducted to compare numerical variables between HBV-positive (anti-HBc positive) and HBV-negative (HBsAg negative and anti-HBc negative) patients with MM. OS was defined as the time between diagnosis and mortality or last documented follow-up. PFS was calculated between the date of diagnosis and progression or mortality. Kaplan-Meier curves for OS and PFS were analyzed with a log-rank test for univariate analyses. Factors with $\mathrm{P}<0.05$ in the univariate analyses were included in multivariate analysis and examined using a Cox regression model. $\mathrm{P}<0.05$ was considered to indicate a statistically significant difference.

\section{Results}

Patient characteristics. Of the 165 patients with MM, 63 (38.2\%) suffered from an acute or chronic HBV infection and resolved HBV infection (HBsAg or anti-HBc positive), and 102 (61.8\%) did not exhibit HBV infection (Table I). The number of patients with active, chronic or resolved HBV infection was 19 (11.51\%), $24(14.54 \%)$ and $20(12.12 \%)$, respectively (data not shown). Furthermore, 37 patients from the whole cohort developed an extramedullary disease (EMD) at the time of diagnosis or during follow-up (Table I). Among the subjects including HBV negative and positive patients, 74 had immunoglobulin (Ig)G type M protein (44.8\%), 43 had IgA type M protein (26.1\%), 36 had light chain type $\mathrm{M}$ protein $(21.8 \%)$ and 12 had other types of M protein, including IgM, IgD and IgE (7.3\%; Table I). According to the R-ISS, $16.3 \%(27 / 165)$ of the patients were classified as stage 3 (Table I). According to the IMWG risk stratification $15.2 \%(25 / 165)$ were described as low risk, $72.7 \%(120 / 165)$ were categorized as moderate risk and $12.1 \%$ $(20 / 165)$ were recorded as high risk (Table I). All the patients underwent at least four cycles of chemotherapy, and $49.1 \%$ $(81 / 165)$ of the cases were treated with bortezomib-containing regimens (Table I). In addition, 16 patients received ASCT following high-dosage chemotherapy.

Comparison of the clinical parameters between patients who were $H B V$-positive and $H B V$-negative. In the present study, patients classified as HBV-positive included those with an acute or chronic HBV infection and resolved HBV infection. Patients classified as HBV-negative were those who had not been infected with HBV. In Table I, the baseline characteristics, including sex, age, type of MM, DS stage, ISS stage, R-ISS stage, IMWG risk stratification, number of bone lesions, ratio of blast plasma cells, presence of EMD, therapeutic regimen and laboratory parameters, were similar among the patients regardless of their HBV status. Table II summarizes the liver-associated laboratory parameters of patients with $\mathrm{MM}$. Patients classified as HBV-positive had liver dysfunction, as indicated by the increased alanine transaminase (ALT) levels (positive vs. negative; 63.29 vs. $24.66 \mathrm{U} / 1 ; \mathrm{P}=0.043$; Fig. 1), compared with patients classified as HBV-negative. The levels of aspartate transaminase, bilirubin, triglyceride, total cholesterol, high-density lipoprotein cholesterol, low-density lipoprotein cholesterol and coagulation function did not significantly differ between the two groups $(\mathrm{P}>0.05)$. The four chromosomal aberrations detected with FISH were as follows: i) Gain of 1q21 (44.2\%); ii) deletion of 13q14 (30.3\%); iii) IGH rearrangements (31.5\%); and iv) deletion of P53 (17.0\%; Table III). The only significant chromosomal aberration was gain of 1q21. In total, $54 \%$ of the patients who were classified as HBV-positive had this chromosomal aberration, which was significantly higher compared with the $38.2 \%$ of the patients who were classified as HBV-negative with the same chromosomal aberration ( $\mathrm{P}=0.048$; Fig. 2). Additionally, the incidence of the three remaining chromosomal abnormalities was higher in patients classified as HBV-positive compared with patients that were HBV-negative; however, these increases were not statistically significant $(\mathrm{P}>0.05)$.

Summary of the six patients with $H B V$ reactivation. In the present study, all patients received lamivudine $(0.1 \mathrm{~g}$ qd), entecavir $(0.5 \mathrm{mg} \mathrm{qd})$ or adefovir dipivoxil $(10 \mathrm{mg} \mathrm{qd})$ for antiviral treatment during the therapy regardless of the quantities of HBV DNA. However, six cases progressed to active infection from chronic HBV infection and the quantity of HBV DNA was $>500 \mathrm{IU} / \mathrm{ml}$ in two patients (cases 2 and 4; Table IV). In four cases, $\mathrm{HBV}$ reactivation developed during induction therapy and the other two cases of HBV reactivation occurred during ASCT. All patients developed the progressive disease (Table IV).

Survival analysis. Multiple clinical parameters were assessed to determine their association with the survival of patients with MM (Table V). The OS of patients classified as HBV-positive was decreased compared with patients classified as HBV-negative; however, this difference was not significant ( 42 vs. 50 months; $P>0.05$; Fig. $3 \mathrm{~A}$ ). In the univariate analyses, age, R-ISS stage, IMWG risk stratification, chromosome, ratio of blast plasma cells, $\beta_{2}$-microglobulin, hemoglobin, lactate dehydrogenase (LDH), serum creatinine and serum calcium levels were identified as significant risk factors of OS (Table V; $\mathrm{P}<0.05$ ). In the multivariate analysis, the LDH level was significantly $>245 \mathrm{IU} / \mathrm{l}$, the serum creatinine level was significantly $>177 \mu \mathrm{mol} / 1$ and the serum calcium level was significantly $>2.65 \mathrm{mmol} / \mathrm{l}$ (Table VI). The PFS was significantly decreased in patients classified as HBV-positive compared with patients classified as HBV-negative (18.97 vs. 29.67 months; $\mathrm{P}=0.006$; Fig. 3B). In the univariate analyses, R-ISS stage, chromosome, EMD, stem cell transplantation, hemogloblin, LDH, serum creatinine and HBV status were identified as significant risk factors of PFS (Table V; $\mathrm{P}<0.05$ ). The multivariate regression analysis of the PFS-influencing factors indicated that HBV-positive status and EMD were considered independent prognostic factors (Table VI). The patients classified as HBV-positive were divided into active infection, chronic infection and resolved infection. The OS of patients with active infection was significantly decreased compared with the other groups $(\mathrm{P}<0.05$; Fig. S1 A). The PFS of patients with active infection, chronic infection and resolved infection was significantly decreased compared with patients classified as HBV-negative $(\mathrm{P}<0.05$; Fig. S1B $)$. 
Table I. Characteristics of 165 patients with MM according to their viral hepatitis status.

\begin{tabular}{|c|c|c|c|}
\hline \multirow[b]{2}{*}{ Characteristic } & \multicolumn{2}{|c|}{ HBV status } & \multirow[b]{2}{*}{ P-value } \\
\hline & Negative $\mathrm{n}(\%)$ & Positive n (\%) & \\
\hline Number of patients & 102 & 63 & \\
\hline Sex & & & 0.083 \\
\hline Male & $49(48)$ & $39(61.9)$ & \\
\hline Female & $53(52)$ & $24(38.1)$ & \\
\hline Age $\geq 65$ years & $34(33.3)$ & $22(34.9)$ & 0.834 \\
\hline Type of MM & & & 0.218 \\
\hline $\operatorname{IgG}$ & $40(39.2)$ & $34(54)$ & \\
\hline $\operatorname{IgA}$ & $27(26.5)$ & $16(25.4)$ & \\
\hline Light chain & $26(25.5)$ & $10(15.9)$ & \\
\hline${ }^{\mathrm{a}}$ Others & $9(8.8)$ & $3(4.8)$ & \\
\hline DS stage & & & 0.541 \\
\hline I & $2(2)$ & $3(4.8)$ & \\
\hline II & $22(21.6)$ & $15(23.8)$ & \\
\hline III & $78(76.4)$ & $45(71.4)$ & \\
\hline ISS & & & 0.702 \\
\hline 1 & $18(17.6)$ & $14(22.2)$ & \\
\hline 2 & $43(42.2)$ & 27 (42.9) & \\
\hline 3 & $41(40.2)$ & $22(34.9)$ & \\
\hline R-ISS & & & 0.337 \\
\hline 1 & $9(8.8)$ & $10(15.9)$ & \\
\hline 2 & $77(75.5)$ & $42(66.7)$ & \\
\hline 3 & $16(15.7)$ & $11(17.5)$ & \\
\hline IMWG risk stratification & & & 0.675 \\
\hline Low risk & $16(15.7)$ & $9(14.3)$ & \\
\hline Moderate risk & $72(70.6)$ & $48(76.2)$ & \\
\hline High risk & $14(13.7)$ & $6(9.5)$ & \\
\hline Number of Bone lesions & & & 0.764 \\
\hline None & $10(9.8)$ & $6(9.5)$ & \\
\hline 1 & $15(14.7)$ & $12(19.0)$ & \\
\hline$\geq 2$ & $77(75.5)$ & $45(71.4)$ & \\
\hline Blast plasma cells $\geq 10 \%$ & $77(75.5)$ & $43(68.3)$ & 0.311 \\
\hline EMD & & & 0.137 \\
\hline No & $83(81.4)$ & $45(71.4)$ & \\
\hline Yes & $19(18.6)$ & $18(28.6)$ & \\
\hline Use of immunomodulatory drugs & $81(79.4)$ & $48(76.2)$ & 0.626 \\
\hline Use of bortezomib & $54(52.9)$ & $27(42.9)$ & 0.208 \\
\hline Stem cell transplantation & $12(11.8)$ & $4(6.3)$ & 0.384 \\
\hline \multicolumn{4}{|l|}{ Baseline laboratory parameters } \\
\hline$\beta 2$-microglobulin $\geq 3.5 \mathrm{mg} / \mathrm{l}$ & $67(65.7)$ & $39(61.9)$ & 0.622 \\
\hline Hemoglobin $<100 \mathrm{~g} / \mathrm{l}$ & $64(62.7)$ & $38(60.3)$ & 0.755 \\
\hline Platelets $<100 \times 10^{9} / 1$ & $17(16.7)$ & $14(22.2)$ & 0.375 \\
\hline Albumin $<35 \mathrm{~g} / 1$ & $46(45.1)$ & $34(54.0)$ & 0.268 \\
\hline Alkaline phosphatase $>185 \mathrm{IU} / 1$ & $2(2.0)$ & $1(1.6)$ & 1.000 \\
\hline Lactate dehydrogenase $>245$ IU/1 & $12(11.8)$ & $11(17.5)$ & 0.305 \\
\hline Serum creatinine $\geq 177 \mu \mathrm{mol} / 1$ & $7(6.9)$ & $8(12.7)$ & 0.266 \\
\hline Serum calcium $>2.65 \mathrm{mmol} / \mathrm{l}$ & $22(21.6)$ & $11(17.5)$ & 0.522 \\
\hline C-reactive protein $>5 \mathrm{mg} / \mathrm{l}$ & $36(35.3)$ & $23(36.5)$ & 0.874 \\
\hline Hepatic cirrhosis & $0(0)$ & $1(1.6)$ & 0.382 \\
\hline
\end{tabular}


Table I. Continued.

\begin{tabular}{lcc}
\hline & \multicolumn{2}{c}{ HBV status } \\
\cline { 2 - 3 } Characteristic & Negative n $(\%)$ & Positive n (\%) \\
\hline HBV status & $102(100)$ & $43(68.3)$ \\
HBsAg negative & 0 & $20(31.7)$ \\
HBsAg positive & $102(100)$ & 0 \\
HBc antibody negative & 0 & $63(100)$ \\
Anti-HBc positive & & P-value \\
\hline a'Others include IgM, IgD, IgE and non-secretory myeloma. MM, multiple myeloma; Ig, immunoglobulin; DS, Durie-Salmon; ISS, International \\
Staging System; R-ISS, Revised-International Staging System; IMWG, International Myeloma Working Group; EMD, extramedullary disease; \\
HBsAg, hepatitis B surface antigen; HBc, hepatitis B core; HBV, hepatitis B virus.
\end{tabular}

Table II. Liver-associated laboratory parameters among patients with multiple myeloma.

\begin{tabular}{|c|c|c|c|}
\hline \multirow[b]{2}{*}{ Biomarkers } & \multicolumn{2}{|c|}{ HBV status } & \multirow[b]{2}{*}{ P-value } \\
\hline & Negative, $n=102$ & Positive, $n=63$ & \\
\hline Alanine transaminase, $\mathrm{U} / \mathrm{l}$ & 24.66 & 63.29 & $0.043^{\mathrm{a}}$ \\
\hline Aspartate transaminase, $\mathrm{U} / \mathrm{l}$ & 27.72 & 38 & 0.085 \\
\hline Total BIL, $\mu \mathrm{mol} / 1$ & 8.66 & 12.41 & 0.092 \\
\hline Direct BIL, $\mu \mathrm{mol} / \mathrm{l}$ & 3.1 & 4.93 & 0.068 \\
\hline Triglyceride, $\mathrm{mmol} / \mathrm{l}$ & 1.52 & 1.4 & 0.377 \\
\hline Total cholesterol, mmol/l & 3.55 & 3.32 & 0.262 \\
\hline High DL, mmol/l & 0.92 & 0.84 & 0.193 \\
\hline Low DL, mmol/1 & 1.82 & 1.72 & 0.522 \\
\hline Activated partial thromboplastin time, sec & 32.13 & 31.74 & 0.792 \\
\hline
\end{tabular}

${ }^{\mathrm{a}} \mathrm{P}<0.05$. BIL, bilirubin; DL, density lipoprotein; HBV, hepatitis B virus.

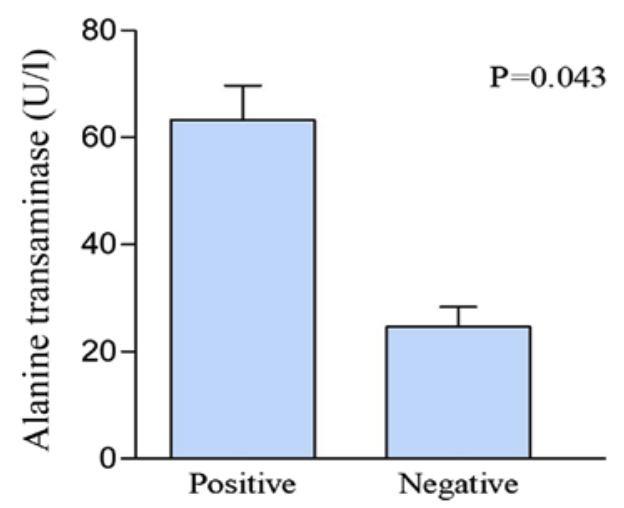

Figure 1. Level of alanine transaminase in HBV-positive and HBV-negative patients with multiple myeloma. HBV, hepatitis B virus.

\section{Discussion}

MM is a B-cell malignancy characterized by the proliferation of clonal plasma cells in bone marrow. It is frequently clinically manifested with hypercalcemia, renal dysfunction, anemia and bone disability (16). The combination of novel induction chemotherapy medications with ASCT is the standard method

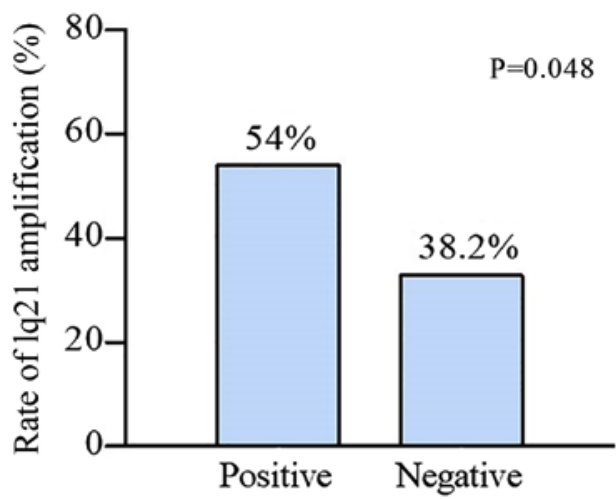

Figure 2. Incidence rates of $1 q 21$ amplification of HBV-positive and HBV-negative patients with multiple myeloma. HBV, hepatitis B virus.

of treatment for patients with MM. However, these patients are highly susceptible to infections as a result of the inhibition of normal Immunoglobulin.

HBV is a small DNA virus belonging to the Hepadnaviridae family, which is characterized by a genome consisting of four overlapping open reading frames: $\mathrm{S}$ gene, core gene, $\mathrm{P}$ gene 
Table III. Association of serological HBV status with chromosomal aberrations.

\begin{tabular}{|c|c|c|c|c|}
\hline \multirow[b]{2}{*}{ Aberration } & \multicolumn{2}{|c|}{ HBV status } & \multicolumn{2}{|l|}{ OR } \\
\hline & Negative $\mathrm{n}(\%)$ & Positive n (\%) & OR (95\% confidence interval) & P-value \\
\hline $1 \mathrm{q} 21+$ & & & $1.894(1.002-3.579)$ & $0.048^{\mathrm{a}}$ \\
\hline 0 & $63(61.8)$ & $29(46.0)$ & & \\
\hline 1 & $39(38.2)$ & $34(54.0)$ & & \\
\hline 13q14- & & & $1.259(0.639-2.479)$ & 0.506 \\
\hline 0 & 73 (71.6) & $42(66.7)$ & & \\
\hline 1 & $29(28.4)$ & $21(33.3)$ & & \\
\hline IGH rearrangements & & & $1.447(0.741-2.827)$ & 0.278 \\
\hline 0 & $73(71.6)$ & $40(63.5)$ & & \\
\hline 1 & $29(28.4)$ & $23(36.5)$ & & \\
\hline P53- & & & $1.058(0.460-2.433)$ & 0.895 \\
\hline 0 & $85(83.3)$ & $52(82.5)$ & & \\
\hline 1 & 17 (16.7) & $11(17.5)$ & & \\
\hline
\end{tabular}

${ }^{\text {a}} \mathrm{P}<0.05$. HBV, hepatitis B virus; 0, negative; 1, positive; +, gain; -, loss; OR, odds ratio; IGH, immunoglobulin heavy locus.

Table IV. Summary of six patients with HBV reactivation.

\begin{tabular}{lcccccccc}
\hline Patient & Sex & Age & Treatment & $\begin{array}{c}\text { Number of } \\
\text { times chemotherapy } \\
\text { was received }\end{array}$ & $\begin{array}{c}\text { HBV DNA, } \\
\text { IU/ml }\end{array}$ & $\begin{array}{c}\text { Time of } \\
\text { reactivation }\end{array}$ & $\begin{array}{c}\text { Anti-HBV } \\
\text { treatment }\end{array}$ & Response \\
\hline 1 & M & 56 & VTD + CTD & 6 & $<500$ & During induction & Entecavir & PD \\
2 & F & 51 & VTD + VD + DECP & 16 & $5.90 \times 10^{3}$ & During induction & Lamivudine & PD \\
3 & M & 65 & VD & 4 & $<500$ & During induction & Entecavir & PD \\
4 & F & 68 & VTD + ASCT & 4 & $1.26 \times 10^{3}$ & During ASCT & Entecavir & PD \\
5 & F & 58 & TD + VAD + MP & 9 & $<500$ & During induction & Lamivudine & PD \\
6 & M & 43 & VTD + ASCT + DVDT & 10 & $<500$ & During ASCT & Entecavir & PD \\
\hline
\end{tabular}

HBV, hepatitis B virus; M, male; F, female; VTD, bortezomib, thalidomide and dexamethasone; CTD, cyclophosphamide, thalidomide and dexamethasone; VD, bortezomib + dexamethasone; DECP, dexamethasone + cyclophosphamide + etoposide + cisplatin; ASCT, autologous stem cell transplant; TD, thalidomide + dexamethasone; VAD, bortezomib + doxorubicin + dexamethasone; MP, melphalan + prednisone; DVDT, liposomal doxorubicin + vincristine + dexamethasone + thalidomide; PD, progressive disease.

and X gene (17). Previous studies have described lymphotropic targeting cells of peripheral blood mononuclear cells, spleen, lymph nodes, thymus and bone marrow $(18,19)$. A previous retrospective case-control trial demonstrated that the HBsAg-positive rate was significantly increased in patients with MM compared with patients with acute leukemia, and HBsAg positivity may be a prognostic factor for patients with MM in HBV-endemic areas (20). China is an area with a high incidence of HBV infection (21). In the present study, the rates of acute and chronic HBV infection in patients with MM were 11.51 and $14.54 \%$, respectively, which were increased compared with the prevalence of these infections in the general population (22).

Rehermann et al (23) determined that HBV is unable to be completely eradicated by the immune response, and HBsAg-negative patients may carry traces of HBV genome in their serum for decades after they clinically recover. HBV is able to replicate through an RNA intermediate, integrate into its host genome, induce genomic aberrations and instability, and remain traceable in resolved HBV infection (HBs Ag negative and anti-HBc positive) (3). The deletion of $8 \mathrm{p}$ chromosome is an important factor in the development of HBV-associated tumors. In hepatocellular carcinoma and MM, the deletion of this chromosome has been observed in $\sim 40 \%$ of the patients classified as HBV-positive compared with 20-30\% of the patients classified as HBV-negative $(24,25)$. Perhaps due to sample size, Becker et al (25) did not identify a significant difference between 1q21 amplification and the pathogenesis of MM. However, the present study identified a statistically significant gain of 1q21 between the patients classified as HBV-positive compared with the patients classified as HBV-negative. Chromodomain-helicase-DNA-binding protein 1-like (CHD1L) overexpression caused by 1q21 amplification may increase cell motility, induce filopodium formation 
Table V. Univariate analysis of survival in patients with MM.

\begin{tabular}{|c|c|c|c|c|}
\hline Characteristic & $\begin{array}{l}\text { Median overall } \\
\text { survival, months }\end{array}$ & P-value & $\begin{array}{l}\text { Median progression-free } \\
\text { survival, months }\end{array}$ & P-value \\
\hline Sex & & 0.688 & & 0.887 \\
\hline Male & 38.20 & & 22.33 & \\
\hline Female & 47.10 & & 22.56 & \\
\hline Age & & $0.035^{\mathrm{a}}$ & & 0.897 \\
\hline$\geq 65$ years & 34.93 & & 20.80 & \\
\hline$<65$ years & 50.00 & & 24.47 & \\
\hline Type of MM & & 0.167 & & 0.378 \\
\hline $\operatorname{IgG}$ & 50.00 & & 25.43 & \\
\hline $\operatorname{IgA}$ & 45.37 & & 19.53 & \\
\hline Light chain & 34.17 & & 18.20 & \\
\hline${ }^{\mathrm{b}}$ Others & NR & & 34.20 & \\
\hline DS stage & & 0.131 & & 0.549 \\
\hline I & NR & & 12.83 & \\
\hline II & 42.20 & & 27.10 & \\
\hline III & 37.88 & & 22.33 & \\
\hline ISS stage & & 0.050 & & 0.193 \\
\hline 1 & NR & & 35.97 & \\
\hline 2 & 43.97 & & 24.10 & \\
\hline 3 & 37.97 & & 20.67 & \\
\hline R-ISS stage & & $<0.001^{\mathrm{a}}$ & & $0.006^{\mathrm{a}}$ \\
\hline 1 & NR & & 35.97 & \\
\hline 2 & 53.47 & & 25.43 & \\
\hline 3 & 28.37 & & 14.50 & \\
\hline IMWG risk stratification & & $0.015^{\mathrm{a}}$ & & 0.442 \\
\hline Low risk & NR & & 32.63 & \\
\hline Moderate risk & 43.97 & & 23.57 & \\
\hline High risk & 23.00 & & 15.73 & \\
\hline Chromosome & & $0.001^{\mathrm{a}}$ & & $0.044^{\mathrm{a}}$ \\
\hline Normal & 54.70 & & 24.47 & \\
\hline Abnormal & 32.10 & & 19.53 & \\
\hline Blast plasma cells & & $0.035^{\mathrm{a}}$ & & 0.078 \\
\hline$\geq 10 \%$ & 42.00 & & 21.50 & \\
\hline$<10 \%$ & NR & & 28.17 & \\
\hline EMD & & 0.862 & & $0.037^{\mathrm{a}}$ \\
\hline Yes & 34.93 & & 19.40 & \\
\hline No & 44.17 & & 25.43 & \\
\hline Use of immunomodulatory drugs & & 0.729 & & 0.523 \\
\hline Yes & 44.17 & & 23.57 & \\
\hline No & 43.97 & & 22.87 & \\
\hline Use of bortezomib & & 0.362 & & 0.196 \\
\hline Yes & 44.17 & & 23.57 & \\
\hline No & 37.97 & & 22.30 & \\
\hline Stem cell transplantation & & 0.200 & & $0.030^{\mathrm{a}}$ \\
\hline Yes & NR & & 58.37 & \\
\hline No & 43.97 & & 22.30 & \\
\hline$\beta 2$-microglobulin & & $0.001^{\mathrm{a}}$ & & 0.059 \\
\hline$\geq 3.5 \mathrm{mg} / 1$ & 36.23 & & 21.50 & \\
\hline$<3.5 \mathrm{mg} / \mathrm{l}$ & NR & & 32.63 & \\
\hline
\end{tabular}


Table V. Continued.

\begin{tabular}{|c|c|c|c|c|}
\hline Characteristic & $\begin{array}{l}\text { Median overall } \\
\text { survival, months }\end{array}$ & P-value & $\begin{array}{l}\text { Median progression-free } \\
\text { survival, months }\end{array}$ & P-value \\
\hline Hemoglobin & & $0.007^{\mathrm{a}}$ & & $0.025^{\mathrm{a}}$ \\
\hline$\geq 100 \mathrm{~g} / \mathrm{l}$ & NR & & 34.03 & \\
\hline$<100 \mathrm{~g} / \mathrm{l}$ & 39.77 & & 20.80 & \\
\hline Platelets & & 0.399 & & 0.270 \\
\hline$\geq 100 \times 10^{9} / 1$ & 44.17 & & 24.10 & \\
\hline$<100 \times 10^{9} / 1$ & 42.00 & & 18.97 & \\
\hline Albumin & & 0.535 & & 0.919 \\
\hline$\geq 35 \mathrm{~g} / 1$ & 45.37 & & 24.47 & \\
\hline$<35 \mathrm{~g} / 1$ & 38.20 & & 19.53 & \\
\hline Lactate dehydrogenase & & $0.023^{\mathrm{a}}$ & & $0.010^{\mathrm{a}}$ \\
\hline$>245 \mathrm{IU} / 1$ & 23.00 & & 10.57 & \\
\hline$\leq 245 \mathrm{IU} / 1$ & 45.00 & & 25.43 & \\
\hline Serum creatinine & & $<0.001^{\mathrm{a}}$ & & $0.003^{\mathrm{a}}$ \\
\hline$\geq 177 \mu \mathrm{mol} / 1$ & 19.43 & & 14.50 & \\
\hline$<177 \mu \mathrm{mol} / \mathrm{l}$ & 47.10 & & 24.10 & \\
\hline Serum calcium & & $0.042^{\mathrm{a}}$ & & 0.324 \\
\hline$>2.65 \mathrm{mmol} / \mathrm{l}$ & 36.23 & & 15.73 & \\
\hline$\leq 2.65 \mathrm{mmol} / \mathrm{l}$ & 45.00 & & 24.10 & \\
\hline C-reactive protein & & 0.364 & & 0.853 \\
\hline$>5 \mathrm{mg} / \mathrm{l}$ & 37.97 & & 24.47 & \\
\hline$\leq 5 \mathrm{mg} / \mathrm{l}$ & 45.36 & & 20.80 & \\
\hline HBV status & & 0.246 & & $0.006^{\mathrm{a}}$ \\
\hline Negative & 50.00 & & 29.67 & \\
\hline Positive & 42.00 & & 18.97 & \\
\hline
\end{tabular}

${ }^{\mathrm{a}} \mathrm{P}<0.05$. ${ }^{\mathrm{b}}$ Others include $\operatorname{IgM}, \operatorname{IgD}, \operatorname{IgE}$ and non-secretory myeloma. MM, multiple myeloma; Ig, immunoglobulin; DS, Durie-Salmon; ISS, International Staging System; R-ISS, Revised-International Staging System; IMWG, International Myeloma Working Group; EMD, extramedullary disease; NR, not reported; HBV, hepatitis B virus.
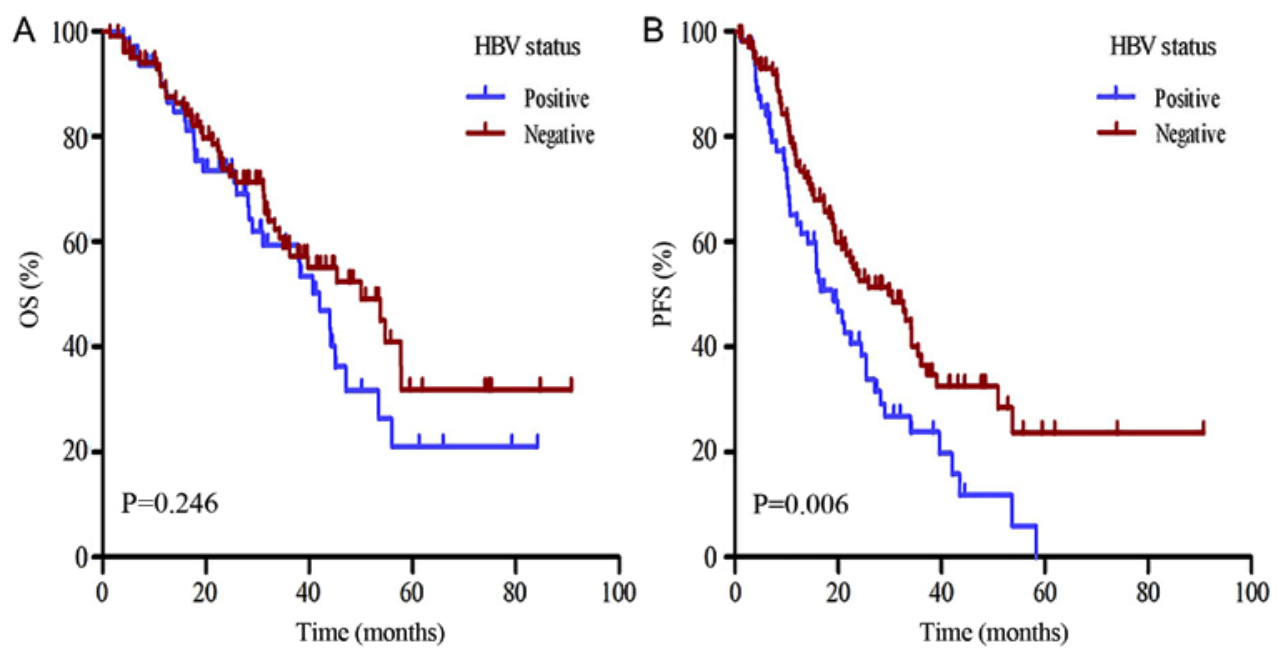

Figure 3. Survival analysis in patients with multiple myeloma according to their viral hepatitis status. (A) OS and (B) PFS demonstrated using Kaplan-Meier curves. HBV, hepatitis B virus; OS, overall survival; PFS, progression-free survival.

and epithelial-mesenchymal transition, which may contribute to tumor cell invasion and metastasis (26). The deregulated overexpression of B-cell lymphoma 9 protein (BCL9) in the pre-B leukemia cell line CEMO-1, suggested that the 
Table VI. Multivariate analysis of survival in patients with multiple myeloma.

A, Overall survival

\begin{tabular}{lccc}
\hline & \multicolumn{3}{c}{ Multivariate analysis ${ }^{\mathrm{b}}$} \\
\cline { 2 - 4 } Parameter & HR & $\begin{array}{c}\text { 95\% confidence } \\
\text { interval }\end{array}$ & P-value \\
\hline Age & 0.613 & $0.364-1.032$ & 0.066 \\
R-ISS stage & 0.964 & $0.486-1.911$ & 0.916 \\
IMWG risk & 0.914 & $0.385-2.172$ & 0.839 \\
stratification & & & \\
Chromosome & 0.696 & $0.398-1.217$ & 0.204 \\
Blast plasma cells & 1.041 & $0.539-2.010$ & 0.905 \\
$\beta_{2}$-microglobulin & 1.539 & $0.782-3.029$ & 0.211 \\
Hemoglobin & 1.678 & $0.879-3.204$ & 0.117 \\
LDH & 2.448 & $1.082-5.537$ & $0.032^{\mathrm{a}}$ \\
Serum creatinine & 2.953 & $1.494-5.836$ & $0.002^{\mathrm{a}}$ \\
Serum calcium & 2.042 & $1.118-3.728$ & $0.020^{\mathrm{a}}$ \\
\hline
\end{tabular}

B, Progression-free survival

\begin{tabular}{lccc}
\hline & \multicolumn{3}{c}{ Multivariate analysis $^{\mathrm{b}}$} \\
\cline { 2 - 4 } Parameter & HR & $\begin{array}{c}\text { 95\% confidence } \\
\text { interval }\end{array}$ & P-value \\
\hline R-ISS stage & 0.781 & $0.428-1.424$ & 0.420 \\
Chromosome & 0.790 & $0.512-1.219$ & 0.286 \\
EMD & 0.488 & $0.289-0.826$ & $0.007^{\mathrm{a}}$ \\
Stem cell & 2.267 & $0.945-5.438$ & 0.067 \\
transplantation & & & \\
Hemoglobin & 1.493 & $0.931-2.394$ & 0.096 \\
LDH & 1.810 & $0.984-3.330$ & 0.056 \\
Serum creatinine & 1.699 & $0.843-3.425$ & 0.138 \\
HBV status & 0.627 & $0.417-0.943$ & $0.025^{\text {a }}$ \\
\hline
\end{tabular}

${ }^{\mathrm{a}} \mathrm{P}<0.05$. ${ }^{\text {b}}$ Variables significant at $\mathrm{P}<0.05$ in the univariate model were entered in the Cox regression multivariate model. R-ISS, Revised International Staging System; IMWG, International Myeloma Working Group; EMD, extramedullary disease; $\mathrm{LDH}$, lactate dehydrogenase; HBV, hepatitis B virus; HR, hazard ratio.

overexpression of BCL9 may be pathogenically essential for B-cell malignancies with breakpoints at 1q21 (27). Therefore, it was hypothesized that HBV infection may contribute to 1q21 amplification and cause MM progression through the overexpression of CHD1L and BCL9; however, this hypothesis requires further investigation with larger cohorts.

$\mathrm{HBV}$ infection induces $\mathrm{B}$ cells to produce specific antibodies that react with antigens on the surface of hepatocytes and cause liver injury, thereby increasing ALT levels (28). Immunosuppressive chemotherapy for MM frequently induces liver dysfunction in patients infected with HBV (29). The present data demonstrated that the level of ALT in patients with HBV infection was significantly increased compared with the non-infected group, and the level of transaminase increased in the majority of the HBsAg-positive patients prior to treatment. Therefore, monitoring the liver function of patients and timely administration of liver-protecting drugs may improve prognoses.

Reactivation of HBV is a well-recognized complication following systemic chemotherapy for hematological malignancies. A previous study identified that Hhigh-dose therapy and ASCT were significant risk factors that were positively associated with HBV reactivation (30). Although all the patients received lamivudine, entecavir or adefovir dipivoxil for an antiviral treatment in the present study, there were six patients with HBV reactivation. These cases received high-dose chemotherapy and two of the cases received ASCT. Therefore, it is necessary to closely monitor the HBV DNA level and antiviral therapy during high-dose chemotherapy and ASCT of patients with MM and HBV infection.

Previous studies on the association of HBV infection with the survival of patients with $\mathrm{MM}$ demonstrated that the OS of HBsAg-positive patients who underwent ASCT was significantly decreased compared with HBsAg-negative patients $(1,31)$. The present data demonstrated that the OS of the patients classified as HBV-positive was decreased compared with the patients classified as HBV-negative; however, this difference was not significant. Therefore, these results differed from previous studies; however, this difference may be attributed to the inclusion of patients with resolved HBV infection. The LDH level was $>245$ IU/1, the serum creatinine level was $>177 \mu \mathrm{mol} / 1$ and the serum calcium level was $>2.65 \mathrm{mmol} / 1$. These parameters were independent factors associated with poor prognosis. These findings were consistent with previous studies $(7,32,33)$. Therefore, an increase in $\mathrm{LDH}$, serum creatinine and serum calcium levels indicated a high tumor mass, suggesting poor prognosis; however, this requires further examination. Additionally, the PFS of the patients classified as HBV-positive and patients classified as HBV-negative was evaluated subsequent to the patients undergoing chemotherapy, and the results demonstrated that the PFS was significantly shorter in the patients classified as HBV-positive. HBV infection was considered an independent prognostic factor of Cox analysis; however, this observation has yet to be demonstrated, to the best of the authors' knowledge. HBV infection promotes T-cell immunoglobulin and mucin-domain containing-3 (Tim-3) expression on Type $1 \mathrm{~T}$ helper cells, and $\mathrm{T}$ cell dysfunction mediated by the Tim-3/galectin- 9 signaling pathway predicted poor prognosis in patients with HBV-associated hepatocellular carcinoma (34). Nevertheless, whether similar mechanisms are responsible for the poor prognosis in patients classified as HBV-positive with MM requires further investigation.

In conclusion, HBV infection may contribute to MM progression through 1q21 amplification and was considered to be an independent prognostic factor among patients with MM. The close monitoring of the level of HBV markers and the timely use of antiviral drugs are crucial for HBV-positive patients.

\section{Acknowledgements}

Not applicable. 


\section{Funding}

The present study was supported by the Jiangsu Provincial Medical Innovation Team (grant no. CXTDA2017046; China).

\section{Availability of data and materials}

The datasets used and/or analyzed during the current study are available from the corresponding author on reasonable request.

\section{Authors' contributions}

DG and PPX contributed to the drafting the manuscript and design of the study. CG contributed to the acquisition, analysis and interpretation of data, YX contributed to the collection and analysis of the data. YY, JX, RZ and BC contributed to the conception and design of the study, and the editing of the manuscript. All authors have read and approved the final version of the manuscript.

\section{Ethics approval and consent to participate}

The Ethics Committee of Nanjing University approved the present study and written informed consent was obtained from all patients.

\section{Patient consent for publication}

All patients consented to the publication of this research.

\section{Competing interests}

The authors declare that they have no competing interests.

\section{References}

1. Li J, Liu J, Huang B, Zheng D, Chen M, Zhou Z, Xu D and Zou W: Hepatitis B virus infection status is an independent risk factor for multiple myeloma patients after autologous hematopoietic stem cell transplantation. Tumour Biol 34: 1723-1728, 2013.

2. Noonan CA, Yoffe B, Mansell PW, Melnick JL and Hollinger FB: Extrachromosomal sequences of hepatitis B virus DNA in peripheral blood mononuclear cells of acquired immune deficiency syndrome patients. Proc Natl Acad Sci USA 83: 5698-5702, 1986.

3. Marcucci F and Mele A: Hepatitis viruses and non-Hodgkin lymphoma: Epidemiology, mechanisms of tumorigenesis, and therapeutic opportunities. Blood 117: 1792-1798, 2011.

4. Smith L, McCourt O, Henrich M, Paton B, Yong K, Wardle J and Fisher A: Multiple myeloma and physical activity: A scoping review. BMJ Open 5: e009576, 2015.

5. Avet-Loiseau H, Bahlis NJ, Chng WJ, Masszi T, Viterbo L, Pour L, Ganly P, Palumbo A, Cavo M, Langer C, et al: Ixazomib significantly prolongs progression-free survival in high-risk relapsed/refractory myeloma patients. Blood 130: 2610-2618, 2017.

6. Becker N, Schnitzler P, Boffetta P, Brennan P, Foretova L, Maynadié M, Nieters A, Staines A, Benavente Y, Cocco P and de Sanjose S: Hepatitis B virus infection and risk of lymphoma: Results of a serological analysis within the European case-control study Epilymph. J Cancer Res Clin Oncol 138: 1993-2001, 2012.

7. Teng CJ, Liu HT, Liu CY, Hsih CH, Pai JT, Gau JP, Liu JH, Chiou TJ, Hsu HC, Chen PM, et al: Chronic hepatitis virus infection in patients with multiple myeloma: Clinical characteristics and outcomes. Clinics (Sao Paulo) 66: 2055-2061, 2011.
8. Rajkumar SV, Dimopoulos MA, Palumbo A, Blade J, Merlini G, Mateos MV, Kumar S, Hillengass J, Kastritis E, Richardson P, et al: International Myeloma Working Group updated criteria for the diagnosis of multiple myeloma. Lancet Oncol 15: e538-e548, 2014.

9. Durie BG and Salmon SE: A clinical staging system for multiple myeloma. Correlation of measured myeloma cell mass with presenting clinical features, response to treatment, and survival. Cancer 36: 842-854, 1975.

10. Greipp PR, San Miguel J, Durie BG, Crowley JJ, Barlogie B, Bladé J, Boccadoro M, Child JA, Avet-Loiseau H, Kyle RA, et al: International staging system for multiple myeloma. J Clin Oncol 23: 3412-3420, 2005.

11. Palumbo A, Avet-Loiseau H, Oliva S, Lokhorst HM, Goldschmidt H, Rosinol L, Richardson P, Caltagirone S, Lahuerta JJ, Facon T, et al: Revised international staging system for multiple myeloma: A report from international Myeloma Working Group. J Clin Oncol 33: 2863-2869, 2015.

12. Kumar S, Paiva B, Anderson KC, Durie B, Landgren O, Moreau P, Munshi N, Lonial S, Bladé J, Mateos MV, et al: International Myeloma Working Group consensus criteria for response and minimal residual disease assessment in multiple myeloma. Lancet Oncol 17: e328-e346, 2016.

13. Huang $\mathrm{H}$ and Chen J: Chromosome bandings. Methods Mol Biol 1541: 59-66, 2017.

14. Simons A, Shaffer LG and Hastings RJ: Cytogenetic nomenclature: Changes in the ISCN 2013 compared to the 2009 edition. Cytogenet Genome Res 141: 1-6, 2013.

15. Li GP, Liu Y, White KL and Bunch TD: Cytogenetic analysis of diploidy in cloned bovine embryos using an improved air-dry karyotyping method. Theriogenology 63: 2434-2444, 2005.

16. Katzel JA, Hari P and Vesole DH: Multiple myeloma: Charging toward a bright future. CA Cancer J Clin 57: 301-318, 2007.

17. Lin CL and Kao JH: Natural history of acute and chronic hepatitis B: The role of HBV genotypes and mutants. Best Pract Res Clin Gastroenterol 31: 249-255, 2017.

18. Michalak TI: Occult persistence and lymphotropism of hepadnaviral infection: Insights from the woodchuck viral hepatitis model. Immunol Rev 174: 98-111, 2000.

19. Sinha M, Rao CR, Premalata CS, Shafiulla M, Lakshmaiah KC, Jacob LA, Babu GK, Viveka BK, Appaji L and Subramanyam JR: Plasma Epstein-Barr virus and Hepatitis B virus in non-Hodgkin lymphomas: Two lymphotropic, potentially oncogenic, latently occurring DNA viruses. Indian J Med Paediatr Oncol 37: 146-151, 2016.

20. Huang B, Li J, Zhou Z, Zheng D, Liu J and Chen M: High prevalence of hepatitis B virus infection in multiple myeloma. Leuk Lymphoma 53: 270-274, 2012.

21. Chen CJ, Wang LY and Yu MW: Epidemiology of hepatitis $\mathrm{B}$ virus infection in the Asia-Pacific region. J Gastroenterol Hepatol 15 (Suppl): E3-E6, 2000.

22. Stasi C, SilvestriC and Voller F: Emerging trends in epidemiology of hepatitis B virus infection. J Clin Transl Hepatol 5: 272-276, 2017.

23. Rehermann B, Ferrari C, Pasquinelli C and Chisari FV: The hepatitis B virus persists for decades after patients' recovery from acute viral hepatitis despite active maintenance of a cytotoxic T-lymphocyte response. Nat Med 2: 1104-1108, 1996.

24. Moinzadeh P, Breuhahn K, Stützer H and Schirmacher P: Chromosome alterations in human hepatocellular carcinomas correlate with aetiology and histological grade-results of an explorative CGH meta-analysis. Br J Cancer 92: 935-941, 2005.

25. Becker N, Byl A, Friedrich S, Jauch A, Schnitzler P, Egerer G, Ho AD, Goldschmidt H and Neben K: Hepatitis B virus infection is associated with deletion of chromosome $8 \mathrm{p}$ in multiple myeloma. Eur J Haematol 90: 279-285, 2013.

26. Chen L, Chan TH and Guan XY: Chromosome 1q21 amplification and oncogenes in hepatocellular carcinoma. Acta Pharmacol Sin 31: 1165-1171, 2010.

27. Willis TG, Zalcberg IR, Coignet LJ, Wlodarska I, Stul M, Jadayel DM, Bastard C, Treleaven JG, Catovsky D, Silva ML and Dyer MJ: Molecular cloning of translocation $\mathrm{t}(1 ; 14)(\mathrm{q} 21 ; \mathrm{q} 32)$ defines a novel gene (BCL9) at chromosome 1q21. Blood 91: 1873-1881, 1998

28. Oh IS and Park SH: Immune-mediated liver injury in hepatitis B virus infection. Immune Netw 15: 191-198, 2015.

29. Bang SM, Kim SS, Park SH, Ahn JY, Cho EK, Shin DB and Lee JH: Acute exacerbation of chronic hepatitis B during thalidomide therapy for multiple myeloma: A case report. Korean J Intern Med 19: 196-198, 2004. 
30. Lee JY, Lim SH, Lee MY, Kim H, Sinn DH, Gwak GY, Choi MS Lee $\mathrm{JH}$, Jung CW, Jang $\mathrm{JH}$, et al: Hepatitis B reactivation in multiple myeloma patients with resolved hepatitis B undergoing chemotherapy. Liver Int 35: 2363-2369, 2015.

31. Li J, Huang B, Li Y, Zheng D, Zhou Z and Liu J: Hepatitis B virus reactivation in patients with multiple myeloma receiving bortezomib-containing regimens followed by autologous stem cell transplant. Leuk Lymphoma 56: 1710-1717, 2015.

32. Dimopoulos MA, Barlogie B, Smith TL and Alexanian R: High serum lactate dehydrogenase level as a marker for drug resistance and short survival in multiple myeloma. Ann Intern Med 115: 931-935, 1991.
33. Maillet D, Montiel-Cervantes L, Padilla-González Y, Sánchez-Cortés E, Xolotl-Castillo M, Vela-Ojed J and Reyes-Maldonado E: Serum calcium is an independent prognostic factor of overall survival in Mexican patients with multiple myeloma. Rev Invest Clin 64: 17-24, 2012.

34. Li H, Wu K, Tao K, Chen L, Zheng Q, Lu X, Liu J, Shi L, Liu C, Wang $\mathrm{G}$ and Zou W: Tim-3/galectin-9 signaling pathway mediates T-cell dysfunction and predicts poor prognosis in patients with hepatitis B virus-associated hepatocellular carcinoma. Hepatology 56: 1342-1351, 2012. 